\title{
Differential influences of social support on app use for diabetes self-management - a mixed methods approach
}

\author{
Nicola Brew-Sam ${ }^{1}$, Arul Chib ${ }^{2}$ (D) and Constanze Rossmann ${ }^{3}$
}

\begin{abstract}
Background: Recent studies increasingly examine social support for diabetes self-management delivered via mHealth. In contrast to previous studies examining social support as an outcome of technology use, or technology as a means for delivering social support, this paper argues that social support has an impact on the use of diabetes mHealth apps. Specifically, we postulate differences between the impact of healthcare professional versus nonprofessional (family/friends) support on mobile app use for diabetes self-management.
\end{abstract}

Methods: This research employed a triangulation of methods including exploratory semi-structured face-to-face interviews ( $N=21$, Study 1$)$ and an online survey ( $N=65$, Study 2$)$ with adult type 1 and type 2 diabetes patients. Thematic analysis (Study 1) was used to explore the relevance of social support (by professionals versus nonprofessionals) for diabetes app use. Binary logistic regression (Study 2) was applied to compare healthcare decisionmaking, healthcare-patient communication, and the support by the personal patient network as predictors of diabetes app use, complemented by other predictors from self-management and technology adoption theory.

Results: The interviews (Study 1) demonstrated that (technology-supported) shared decision-making and supportive communication by healthcare professionals depended on their medical specialty. The personal patient network was perceived as either facilitating or hindering the use of mHealth for self-management. Binary logistic regression (Study 2) showed that the physician specialty significantly predicted the use of diabetes apps, with supervision by diabetes specialists increasing the likelihood of app use (as opposed to general practitioners). Additionally, specialist care positively related to a higher chance of shared decision-making and better physicianpatient communication. The support by the personal patient network predicted diabetes app use in the opposite direction, with less family/friend support increasing the likelihood of app use.

Conclusion: The results emphasize the relevance of support by healthcare professionals and by the patient network for diabetes app use and disclose differences from the existing literature. In particular, the use of diabetes apps may increase in the absence of social support by family or friends (e.g., compensation for lack of support), and may decrease when such support is high (e.g., no perceived need to use technology).

Keywords: mHealth, Apps, Technology, Diabetes, Self-management, Social support, Shared decision-making

\footnotetext{
* Correspondence: ArulChib@ntu.edu.sg

${ }^{2}$ Wee Kim Wee School of Communication and Information, Nanyang

Technological University, 31 Nanyang Link, Singapore 637718, Singapore

Full list of author information is available at the end of the article
} 


\section{Background}

Prior research has suggested the impact of social support on diabetes management and health outcomes $[1,2]$. With technological advances in healthcare, recent studies increasingly examine social support for diabetes selfmanagement delivered through mobile online technologies (mHealth) (e.g. [3]). In this context, most studies considered social support as an outcome of mHealth use, or mHealth as a means for delivering social support. Applying a novel perspective to mHealth research, our paper investigates the influence of social support on the use of mHealth (apps), as implicated by technology adoption models.

In this paper, we distinguish between the impact of varied types of social support on diabetes self-management and outcomes in previous studies, further arguing that these sources of social support differentially influence technology-supported diabetes self-management. In particular, we identify and examine the varied influence of support by healthcare professionals and by the personal social patient network on the use of diabetes selfmanagement apps. A separate study conducted on diabetes app quality and app features, as factors of interest, has been reported elsewhere $[4,5]$.

\section{The relevance of social support for diabetes self- management}

Patient self-management, in which patients are decisionmakers in control of their daily diabetes management [6], moved to the core of diabetes care when research revealed that patient non-compliance rates were high in care approaches based solely on healthcare professional responsibility ("doctor knows best principle") [6]. Wilkinson, Whitehead, and Ritchie [7] reported that the ability to self-manage a diabetic condition (e.g., diet adherence, physical activity, medication intake, managing psychological aspects $[8,9])$ is influenced by a whole series of factors (e.g., in $[10,11])$. Prominently, social support has been reported to influence self-management behaviors and outcomes, associated with improved patient lifestyle and clinical outcomes, and reduced psychosocial disease symptoms [2]. The impact of support has been distinguished between that provided by healthcare professionals [12-14] and by the personal social patient network like relatives or peers [15-17]. This impact on diabetes management and health outcomes has been examined extensively, and been compared to one another ( $[1,18]$; also see [4]).

First, studies on professional support show the beneficial effects of professional support on diabetes outcomes [19], especially when health professionals empower patients by using shared decision-making and supportive communication. A collaborative process of joint decision-making with an active contribution from both parties and the involvement of patients in treatment decisions (providing choices, considering patient preferences, and encouraging them to ask questions $[13,19,20])$ have been shown to be most supportive in disease care [21].

Second, in terms of non-professional support, family and friends can deliver emotional and practical support daily in diabetes care [22-25]. However, the personal social patient network has been reported to have a negative impact on diabetes self-management and health outcomes, when interactions like nagging behaviors, a lack in understanding, too much sympathy or pity expressed, or other negative behaviors occur [16, 26-29]. The concept of "miscarried helping" represents some of these problems [30].

\section{Social support and technology-supported diabetes self- management}

Research has shown that interventions and care approaches need to differentially address support by the professional system and by the patient's personal network for achieving improved outcomes [1]. This distinction applies similarly to research related to technologysupported diabetes care [31], which includes the use of diabetes apps that are designed to help patients improve their self-management (e.g., logbook apps).

In previous research, the use of (e.g., cloud-based) technology for support by healthcare professionals was reported to mostly result in positive outcomes for diabetes self-management [32-34]. Wehbe, Curcio, Gajjar, and Yadlapati [35] stated that the integration of technology into diabetes care affects physician-patient relationships positively when discussions are facilitated and when shared decision-making between physicians and patients is improved. However, according to these authors, the higher workload for physicians can also affect the relationship negatively. Abbasgholizadeh, Menear, Robitaille, and Legare [36] reported that health apps have potential for improved patient participation in shared health decisionmaking, but bear risks like security concerns or increased patient anxiety.

Beneficial effects of technology use on self-management and health outcomes were typically reported in studies that addressed non-professional social support by the patient's personal networks $[37,38]$. The use of social media, online communities, or mobile health (mHealth) has enhanced or improved psychological empowerment $[39,40]$, self-care information and knowledge [38, 41], blood glucose levels (HbA1c), as well as glucose self-monitoring and physical activity [3, 42], and other health aspects [43-45]. The inclusion of family members or spouses in technological diabetes management systems was found to improve their understanding of self-management requirements and affected the communication about diabetes and the support of the patient positively [46]. Notably, different studies reported 
that online social support by non-professionals might not always result in beneficial self-management and health outcomes. For example, this occurs when participation in online communities leads to mismatches between needed and received support, or when support hinders health improvements for patients with high self-efficacy [47].

\section{Research gap: the influence of (non-) professional social support on technology use}

Existing studies almost exclusively focused on social support as an outcome of technology use, or on technology as a means for delivering social support. However, in order to increase an understanding of factors that influence technology use for self-care, research is still required that examines how professional and non-professional social support affect (mobile) diabetes technology use. It can be assumed that social support influences the use of mobile diabetes technology (e.g., apps) just as much as it influences traditional diabetes self-management behaviors (blood glucose testing, healthy nutrition, exercise, etc.) [4].

The number of studies examining factors influencing mHealth use is steadily rising [48], particularly in the context of disease self-management $[49,50]$. While theoretical models of technology adoption [51] are one step towards understanding factors that influence (mobile) technology adoption and use, there is a gap in proving both significant and substantive usage effects for mHealth [52, 53]. Previous studies investigated factors influencing mHealth use in specific target groups (e.g. $[54,55])$, for specific diseases or health topics [56-60], and for sustained mHealth engagement [61]. This study aims to explicate the effect of social support.

Social support has been shown to play a role as an influencing factor on aspects of technology use in mHealth studies. Zhang et al. [59], for instance, found that the theoretical factors of social influence and performance expectancy had the strongest direct influence on behavioral intention to use diabetes apps for disease management. Likewise, Quaosar et al. [55] found that social influence had a significant impact on intention to use mHealth, specifically in populations of higher age. We aim to address the research gap in these studies by comparing differential influences of healthcare professionals and personal patient networks on technology for self-care.

We hypothesize that both professional (e.g., physician) and non-professional support (e.g., family and friends) differentially influence diabetes app use (as a technologysupported self-management behavior). Following previous diabetes research it can be assumed that: (H1) shared decision-making styles and supportive communication of healthcare professionals are promoting technologysupported self-management (app use), while (H2) the impact of support by the patient's personal social network on technology (app) use for self-management depends on the type of perceived support (positive or misguided).

\section{Methods}

We used a mixed methods approach that included qualitative and quantitative data collection and analysis to permit "a more complete and synergistic utilization of data" ([62] , p.1). A detailed description of the methodology can be found in Brew-Sam $[4,63]$.

\section{Study 1: semi-structured face-to-face interviews}

In the first study we conducted $21 \mathrm{semi}$-structured faceto-face interviews with type 1 (T1DM) and type 2 (T2DM) adult diabetes patients in Singapore. The interview guide [63] included questions on patients' previous diabetes app (non-) use, their diabetes self-management, their attitudes, the support received from their medical team, relatives, and from others, as well as other relevant factors from self-management [7] and technology adoption theories, such as Unified Theory of Acceptance and Use of Technology (UTAUT) [51].

In addition to an interview guide developed based on these theories, we used a standardized background information questionnaire to collect relevant information about the patient background (e.g., demographic data, disease information) [63]. Open questions collected information about app and technology (non-) use as part of the diabetes self-management, as well as professional and non-professional social support, including shared decision-making in the patients' treatment, their communication with healthcare professionals, and the support they received from their personal social network. Regarding the latter, we focused on family and friends' support, being their strong-tie partners [64].

Ethics approval was sought and approved by the Nanyang Technological University Review Board (IRB2016-01-012). Purposive sampling included patients with a variety of demographic and disease characteristics. Participants were informed about the study purpose and signed informed consent forms. All interviews were conducted by one researcher in English. The interviews were conducted and transcribed in 2015/2016 using the audio recording software "Audacity". The audio files were completely and manually transcribed by three research assistants (explicit verbal content only); the cadence and cultural speech patterns have been retained for accuracy. The accuracy of transcription was checked, and names of interview participants were anonymized (interview participant/IP numbers).

Thematic analysis, as described by Braun and Clarke [65], was used for data analysis, following established standards for qualitative research [66]. A theme was defined as a topic resulting from different interview statements with similar content. First, preliminary categories 
were developed from the interviews regarding technology use, self-management, and social support using a matrix for data extracts. Broad themes were developed from the categories, which were reviewed against data extracts and the entire data set, before results were analyzed and interpreted (discussion among multiple researchers where results were ambiguous). A diabetes app (non-) user typology summarized the results on emerging themes and to map out differences in social support for different groups.

\section{Study 2: standardized online survey}

In the second study we conducted a standardized online survey with 65 type 1 and type 2 diabetes patients. The questionnaire included questions on their diabetes background, self-management behaviors, mHealth use, social support, general attitudes and feelings, psychological empowerment, and demography [63].

Previous diabetes app use or non-use, as well as the length and frequency of previous app use were measured based on the National Survey on Health App Use [67]. Decision-making styles by health professionals and communication with the patient were measured using the Provider Participatory Decision-making Style Scale [13] (PDMstyle, $M=3.25, S D=.08, \alpha=.943$ ) and the Provider Communication Scale [13] (PCOM, $M=3.50, S D=.37$, $\alpha=.919$ ). Items from these scales, for example, asked to "specify how often the doctors or health care professionals who take care of your diabetes offered you choices in your medical care" (PDMstyle, "none of the time" to "all of the time") and "tell us how the doctors or health care professionals who take care of your diabetes are at explaining treatment alternatives" (PCOM, "poor" to "excellent"). 5point Likert scales were used throughout the survey. Social support by the personal social patient network was measured with a scale on support by family and friends from the Diabetes Care Profile (DCP, section V, $M=3.29$, $S D=.19, \alpha=.931)[68,69]$. Scale items included questions on support delivered by family and friends, for example, "my family or friends help and support me a lot to take my medicine" (DCP, "strongly agree" to "strongly disagree"). Diabetes background and self-management data were adapted from the Diabetes Care Profile [69], two psychological empowerment scales [70, 71], the National Survey on Health App Use [67], and the Summary of Diabetes Self-Care Activities [72].

The survey was pre-tested with sixteen participants with and without diabetes. The online survey was disseminated (snowball method) to former face-to-face interview participants, as well as through social media and diabetes support groups. A lottery participation (monetary incentives: three coupons of 100 SGD each) was offered at the end of the survey.
Binary logistic regression (enter, blockwise) was used to test $H 1$ and $H 2$ on social support by health professionals versus non-professionals (family and friends) influencing diabetes app use, and to compare the strength of both (and other relevant included self-management and diabetes background factors from self-management and technology adoption theory) on diabetes app use. Independent variables were metric or coded as dummy variables, while diabetes app use was used as a binary variable (previous diabetes app use or non-use). Independent factors that included data from both app users and non-users were used in binary logistic regression. Regression models were compared for model fit, prediction success, and the inclusion of significant predictors by starting with all available factors, and then removing factors step by step.

\section{Study samples}

Table 1 summarizes demographic and disease characteristics of the interview (Study 1,N=21) and the online survey samples (Study 2, $N=65$ ). Overall, the samples were diverse, including diabetes patients from various demographic and disease-related subgroups. The interview sample mostly included active patients managing their condition, with five respondents at high risk for health complications due to lacking diabetes knowledge, lacking motivation and insufficient self-management, unfavorable self-management attitudes, and/or critical health conditions (e.g., high blood glucose values). In both samples there were more type 2 diabetes patients than type 1 diabetes patients, following the global prevalence ( 90\%) of type 2 diabetes [73].

\section{Results}

\section{Interview results on social support and diabetes app use} (Study 1)

As a foundation for comprehensively examining the influence of $(H 1)$ professional and $(H 2)$ non-professional support on diabetes app use, and to specify the hypotheses, themes were extracted from the interview data, relating to the aspects "previous app use for diabetes management", "professional support", and "non-professional support". Table 2 summarizes the results in form of a diabetes app (non-) user typology, which displays the differences in social support in differing app user and non-user groups.

\section{Diabetes app (non-) use in the sample - description of the dependent variable}

App (non-) use categories ranged from "no previous use", "(no) interest in apps", and "(no) knowledge about existing diabetes management apps", to "infrequent and short-term app use" to "long-term app use". Some interview participants had never used diabetes apps for self- 
Table 1 Description of Study 1 and Study 2 Samples

\begin{tabular}{|c|c|c|c|c|c|c|c|c|c|c|c|c|}
\hline \multirow[b]{2}{*}{ Variable } & \multicolumn{6}{|c|}{ Study 1 - Interviews } & \multicolumn{6}{|c|}{ Study 2 - Survey } \\
\hline & $n$ & $\%$ of $N$ & M & SD & Min & Max & $n$ & $\%$ of $N$ & M & SD & Min & Max \\
\hline Age (in years) & - & - & 48.35 & 17.46 & 19.00 & 68.00 & - & - & 49.74 & 14.67 & 20.00 & 70.00 \\
\hline \multicolumn{13}{|l|}{ Education } \\
\hline MA graduate or higher & - & - & & & & & 15 & 23.1 & & & & \\
\hline BA graduate/college graduate & 6 & 28.6 & & & & & 22 & 33.8 & & & & \\
\hline Some college & 7 & 33.3 & & & & & 12 & 18.5 & & & & \\
\hline High school graduate & 1 & 4.8 & & & & & 12 & 18.5 & & & & \\
\hline Some high school & 4 & 19.0 & & & & & 3 & 4.6 & & & & \\
\hline Other education level & 1 & 4.8 & & & & & 1 & 1.5 & & & & \\
\hline \multicolumn{13}{|l|}{ Employment } \\
\hline Full- time working & 8 & 38.1 & & & & & 34 & 52.3 & & & & \\
\hline Part-time working & 3 & 14.3 & & & & & 12 & 18.5 & & & & \\
\hline Homemaker & 3 & 14.3 & & & & & 1 & 1.5 & & & & \\
\hline Retired & 3 & 14.3 & & & & & 7 & 10.8 & & & & \\
\hline Student & 3 & 14.3 & & & & & 5 & 7.7 & & & & \\
\hline Unemployed & - & - & & & & & 6 & 9.3 & & & & \\
\hline \multicolumn{13}{|l|}{ Family status } \\
\hline Married & 9 & 42.9 & & & & & 32 & 49.2 & & & & \\
\hline Never married & 8 & 38.1 & & & & & 18 & 27.7 & & & & \\
\hline Never married but relationship & - & - & & & & & 4 & 6.2 & & & & \\
\hline Separated/divorced & 1 & 4.8 & & & & & 7 & 10.8 & & & & \\
\hline Widowed & 1 & 4.8 & & & & & 4 & 6.2 & & & & \\
\hline \multicolumn{13}{|l|}{ Gender } \\
\hline Men & 11 & 52.4 & & & & & 32 & 49.2 & & & & \\
\hline Women & 10 & 47.6 & & & & & 33 & 50.8 & & & & \\
\hline \multicolumn{13}{|l|}{ Nationality } \\
\hline Singaporean & 19 & 90.5 & & & & & 57 & 87.7 & & & & \\
\hline Malaysian & 1 & 4.8 & & & & & 4 & 6.2 & & & & \\
\hline Other & 1 & 4.8 & & & & & 4 & 6.2 & & & & \\
\hline \multicolumn{13}{|l|}{ Diabetes Background } \\
\hline Diabetes family history & 12 & 57.1 & & & & & 50 & 76.9 & & & & \\
\hline \multicolumn{13}{|l|}{ Diabetes type } \\
\hline T2DM (incl. gestational) & 11 & 52.4 & & & & & 50 & 76.9 & & & & \\
\hline T1DM & 9 & 42.9 & & & & & 13 & 20.0 & & & & \\
\hline Pre-diabetes & 1 & 4.8 & & & & & 2 & 3.1 & & & & \\
\hline Diseases (other) & 8 & 38.1 & & & & & - & - & & & & \\
\hline Education on diabetes (received) & 17 & 81.0 & & & & & 50 & 76.9 & & & & \\
\hline Length of diabetes (in years) & - & - & 19.89 & 12.07 & 4.00 & 38.00 & - & - & 13.73 & 9.81 & .00 & 36.00 \\
\hline \multicolumn{13}{|l|}{ Medication } \\
\hline Insulin injection (syringe or pump) & 14 & 66.7 & & & & & 25 & 38.5 & & & & \\
\hline Oral diabetes medication & 10 & 47.6 & & & & & 51 & 78.5 & & & & \\
\hline
\end{tabular}

(Self-) Management

Check-up frequency (in months) 
Table 1 Description of Study 1 and Study 2 Samples (Continued)

\begin{tabular}{|c|c|c|c|c|c|c|c|c|c|c|c|c|}
\hline \multirow[b]{2}{*}{ Variable } & \multicolumn{6}{|c|}{ Study 1 - Interviews } & \multicolumn{6}{|c|}{ Study 2 - Survey } \\
\hline & $\bar{n}$ & $\%$ of $N$ & M & SD & Min & Max & $n$ & $\%$ of $N$ & M & SD & Min & Max \\
\hline Diabetes app use & 11 & 52.4 & & & & & - & - & & & & \\
\hline Never used & - & - & & & & & 34 & 52.3 & & & & \\
\hline Previous use & - & - & & & & & 17 & 26.2 & & & & \\
\hline Current use & - & - & & & & & 14 & 21.5 & & & & \\
\hline Online health information seeking (Study 2: days per week) & 19 & 90.5 & - & - & - & - & - & - & 2.70 & 2.27 & .00 & 7.00 \\
\hline Part of support group & 15 & 71.4 & & & & & - & - & & & & \\
\hline Offline & - & - & & & & & 42 & 64.6 & & & & \\
\hline Online & - & - & & & & & 19 & 29.2 & & & & \\
\hline Part of diabetes program & 2 & 9.5 & & & & & 7 & 10.8 & & & & \\
\hline
\end{tabular}

Note. Table based on Brew-Sam [4]; Study 1: $N=21$, Study 2: $N=65$

management before and expressed no interest in them (e.g., IP8, IP9), while others showed interest but lacked knowledge about appropriate app use (e.g., IP4, IP15). Most participants were familiar with available diabetes apps (apart from a few without any knowledge about app availability, e.g., IP12 and IP15). Reported diabetesspecific app use was almost exclusively limited to logbooks for blood glucose monitoring (e.g., DAFNE online App, MySugr, Glooko, DiabetesM) and to food databases displaying nutritional information (e.g., food database app developed by the Singaporean Health Promotion Board). Moreover, app users split into short-term users who were mostly unsatisfied with the current state of diabetes apps and had abandoned their use after a while ("adopters", e.g., IP16, IP11), users who constantly switched apps, using several in parallel ("switchers", e.g., IP3, IP21), and users who used one main app over a longer period of time ("long-term users", e.g., IP5, IP6) (Table 2).

\section{Professional support - physician-patient relationship}

The themes derived from the interviews regarding healthcare professional support in (technology-supported) diabetes management included "medical specialty of physician related to perceived care quality", "taking time for communication", "actual decision-making”, "decision-making preferences", and "inclusion of apps in physician-patient relationship".

Physicians were mentioned as the main supervisors in diabetes care, with other healthcare professionals (e.g., dieticians, nurse educators, podiatrists, pharmacists) only partly included in care with considerable variation amongst respondents (IP2, IP3, IP6, IP7). Thus, we further focused on the physician-patient relationship.

Patients supervised by general practitioners (GPs) reported short consultations with brief physician-patient communication ("the doctor is 5-10 minutes only", IP2, age 56-60, T2DM; "if you ask questions, they will answer... but they won't engage you for too long”, IP8, age
61-65, T1DM), perceived GPs lacking diabetes knowledge, and a perceived lack in support ("they [physicians] are not helpful", IP4, age 46-50, T2DM). They mostly expressed dissatisfaction with the quality of supervision by their GPs. The group of dependent patients, defined as those mainly following doctors' instructions without taking diabetes-related decisions or being less active in decision-making (e.g., IP12, age 61-65, T2DM), mostly consulted GPs. Additionally, non-users of apps mostly consulted GPs (Table 2).

In contrast to GPs, diabetes specialists were reported as providing adequate time for support: "you got two types [of physicians]... one we call it family physician... one uh he charge you more, double [specialist]... this doctor will spend more time" (IP3, age 66-70, T2DM). Moreover, specialists sometimes developed close relationships with their patients ("he's... more like a family friend ... than a doctor", IP6, age 56-60, T2DM) and mostly followed shared decision-making approaches. Yet, some patients considered their physicians merely as advisors, preferring to take diabetes care decisions independently (e.g., IP1, IP3) (Table 2).

Overall, few patients reported that physicians or other healthcare professionals (nurses) talked about diabetes apps in the consultations, or shared app information with them (e.g., IP2, IP3, IP6). Some patients participated in diabetes programs (e.g., DAFNE, dose adjustment for normal eating) that included specialist supervision and an app for self-management (e.g., IP1, IP19). Apart from these specialist programs, physicians hardly used apps to communicate with their patients (sometimes Email, e.g., IP5).

\section{Non-professional support - family \& friends' support}

Self-management support by family and by friends fell into the categories of "managing alone", "negative support", "involvement only after diagnosis", and "strong involvement". Both app users and non-users reported 


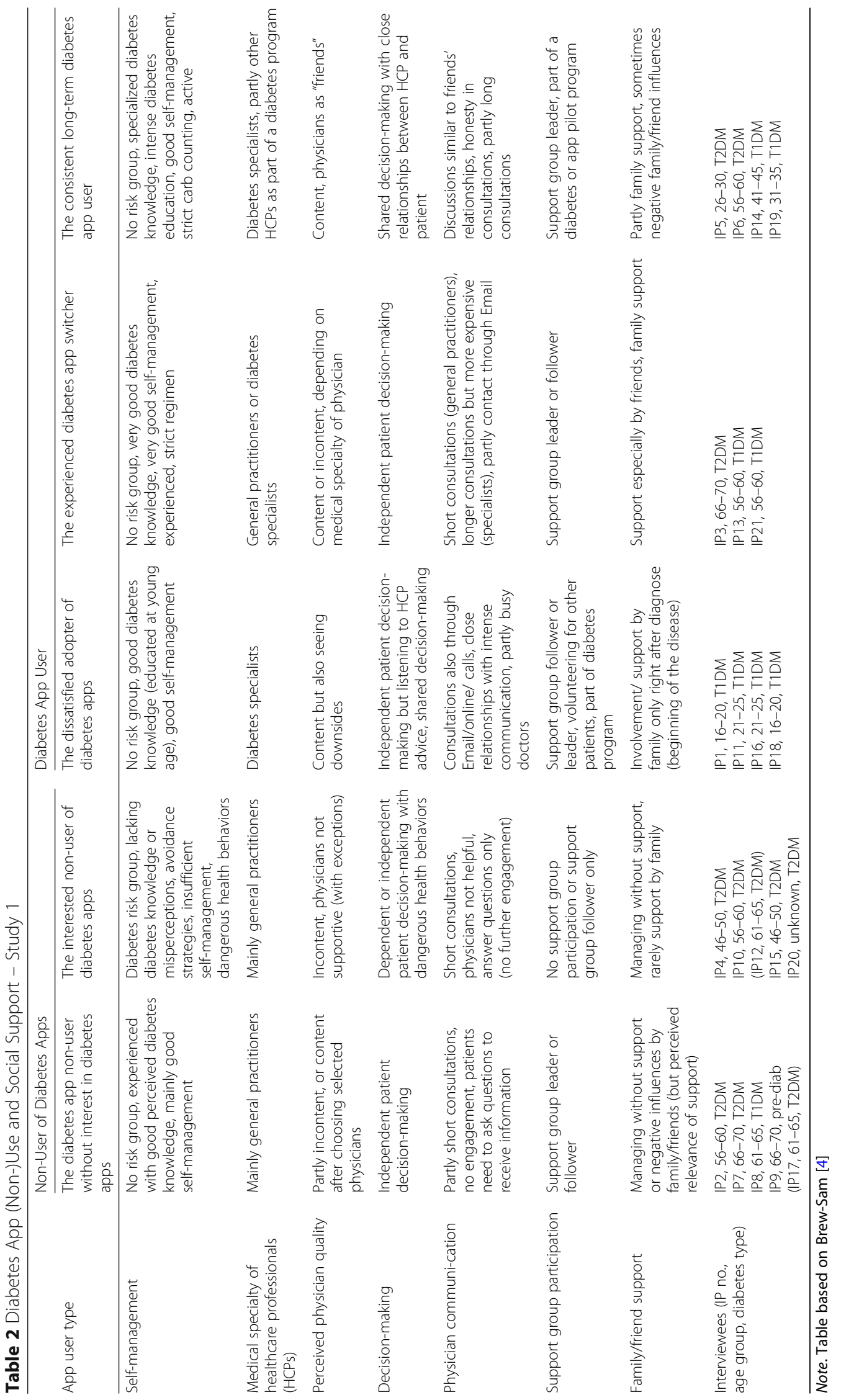


receiving support by their family and friends in their diabetes management (Table 2), either after diagnosis at the beginning of self-care (e.g., IP11, IP18) or throughout the whole process of self-care (e.g., IP21, IP13). Negative support was reported when their social contacts tempted the patients towards unhealthy lifestyles, e.g., "they always say 'never mind! Eat, just eat! Only once! You don't eat this every day" (IP9, age 66-70, pre-diabetes), or when involvement of the family resulted in nagging behaviors ("whenever they are with me... when the doctor tells me something... and then after ... when we go home they immediately start nagging me", IP16, age 2125, T1DM). Positive attitudes towards diabetes care by family and friends were mentioned as important for selfmanagement ("the key is that they're... not uhh... really that negative on this... they're also very positive", IP13, age 56-60, T1DM). Some non-users of diabetes apps said they managed their condition alone, without the involvement of family or friends ("It's myself, nobody else... No friends, no, nobody else, it is me", IP8, age 61-65, T1DM).

Overall, the interviews showed that aspects of professional support (style of decision-making, duration and quality of communication) related to perceptions of satisfaction and success in self-management. Moreover, this appeared to be influenced by the medical specialty of the physician supervising the patient (compare [4]). Regarding non-professional support, the support by family and friends diversely related to (technology-supported) selfcare, with both positive and negative influences on selfmanagement reported. Based on the exploratory interview results we specified the theoretically derived hypotheses $H 1$ and $H 2$ as following:

(H1a) Supportive behaviors by the supervising physician (shared decision-making styles and supportive communication) positively predict diabetes app use for self-management.

(H1b) The medical specialty of the supervising physician (specialist versus GP) is a predictor of diabetes app use for self-management, with specialist care promoting app use to a greater extent than care by GPs.

(H2a) (Positive) support by the patient's personal social network (family and friends) positively predicts diabetes app use for self-management.

\section{Online survey results on social support and diabetes app use (Study 2)}

In Study 2 we tested hypotheses $H 1 a, H 1 b$, and $H 2 a$ using binary logistic regression. Checking for autocorrelation of all independent variables, physician decisionmaking and physician-patient communication were highly correlated with $r=.772, p<.01$. Therefore, decision-making and communication were recoded into a single variable "physician-patient relationship" [4].

Based on theoretical considerations and the interview results, we began with a binary logistic regression model that included a maximum of independent factors: physician-patient relationship, medical specialty of the physician, family/friend support, and other relevant factors from technology adoption theory [(51] and from self-management theory [7] shown to be relevant predictors of technology use for disease self-management. We then compared different models by reducing independent factors to find the model with the best fit.

A model with good fit included the factors derived from the interviews physician-patient relationship, family/friend support, medical specialty of the physician, as well as the additional UTAUT factors' perceived app potential (performance and effort expectancy), previous health information seeking online (technological experience), and age; and the self-management factors type of diabetes, length of diabetes, perceived health status, payment problems and insurance coverage (socioeconomic), blood glucose testing adherence (self-management behaviors), interest in innovation (attitudes), perceived diabetes knowledge, program or support group participation, and psychological empowerment. The test of this model against the constant-only model was statistically significant, indicating that the predictors as a set reliably distinguished between diabetes app use and non-use $\left(\chi^{2}(16)=26.752, p<.05\right)$. Nagelkerke's $R^{2}=.656$ indicated a high relationship between prediction and grouping (goodness-of-fit). Prediction success overall was $90 \%$ (80\% for app non-use and $96 \%$ for app use). The Wald criterion demonstrated that only the family/friend support (Wald $(1)=5.315, p=.021$ ) and the medical specialty of the consulted physician (dummy GP or specialist, Wald $(1)=4.014, p=.045$ ) made a significant contribution to the prediction of diabetes app use. The $\operatorname{Exp}(\beta)$ value indicated that when the family/friend support was increased, the relative probability (odds ratio) that diabetes apps were used decreased with $\operatorname{Exp}(\beta)=$ $.044, \beta=-3.131$. The $\operatorname{Exp}(\beta)$ value indicated that when the patients were supervised by specialist doctors the relative probability (odds ratio) that diabetes apps were used increased with $\operatorname{Exp}(\beta)=9460.805, \beta=9.155$. In contrast to non-professional support (family/friends), the physician-patient relationship was not found to be a significant predictor in the model.

A model resulting after the removal of the factors interest in innovation, insurance coverage, and program or support group participation (due to lacking significance) showed a slightly lower prediction success with $75 \%$ (70\% for app non-use and 79\% for app use), but overall model significance with $\chi^{2}(13)=26.936, p<.05$, 
and a moderate to high relationship between prediction and grouping (goodness of fit) with Nagelkerke's $R^{2}=.509$. In this model, the Wald criterion demonstrated that the family/friend support (Wald $(1)=6.617, p=.010$ ) and perceived health status (Wald $(1)=7.839, p=.005$ ) made a significant contribution to the prediction of diabetes app use. Again, the $\operatorname{Exp}(\beta)$ value showed that when support by family/friends was increased, the relative probability (odds ratio) that diabetes apps were used decreased with $\operatorname{Exp}(\beta)=$ .283, $\beta=-1.261$. The $\operatorname{Exp}(\beta)$ value also indicated that when the perceived health status was improved the relative probability (odds ratio) that diabetes apps were used increased with $\operatorname{Exp}(\beta)=8.030, \beta=2.083$.

Further reducing the independent factors, the models showed similar results to the last model, resulting in family/friend support and the perceived health status being significant predictors of diabetes app use. A further reduction of factors decreased the model fit, yet the medical specialty of the physician nearly reached significance again.

Overall, after testing various models, only the family/ friend support, the medical specialty of the supervising physician, and the perceived health status significantly predicted diabetes app use. Less family/friend support was likely leading to a higher chance of diabetes app use, while the use of diabetes specialists or a better perceived health status increased the chance of app use for selfmanagement.

Despite the physician-patient relationship lacking significance for predicting diabetes app use in the models (apart from the medical specialty of the physician as a significant predictor), additional $t$-test calculations showed that the medical specialty of the physician related to the style of decision-making and the physician-patient communication. There were differences between specialists and GPs, with specialist care positively related to higher shared decision-making and better physician-patient communication as compared to GPs (Decision-making PDMstyle: specialists: $M=3.72, S D=1.16, n=37$, general practitioners: $M=2.65, S D=1.30, n=22 ; t[57]=-3.275$, $p<.01, N=59$; Communication PCOM: specialists: $M=$ 3.82, $S D=1.01, n=37$, general practitioners: $M=3.13$, $S D=1.09, n=22 ; t[57]=-2.472, p<.05, N=59)(\mathrm{com}-$ pare [4]).

\section{Discussion}

In general, this two-study project found that social support from both professional and patient's personal social networks had an influence on mobile app usage in the context of diabetes self-care.

Regarding professional support, the interviews (Study 1) showed that shared decision-making and supportive communication, including support regarding diabetes technology use, depended on the medical specialty of the physician, with patients perceiving support by diabetes specialists as more helpful than by GPs. Binary logistic regression (Study 2) confirmed these results, showing that the specialty of the physician significantly predicted the use of diabetes apps by patients, with supervision by diabetes specialists increasing the likelihood of the apps being used (as opposed to GPs). Specialist care was positively related to higher shared decision-making and better physician-patient communication. These study results conform with existing research, which points towards differences in diabetes care depending on the medical specialty of the supervising physician.

A study by Koizumi et al. [74], for example, reported that attitudes towards glucose control and self-care varied in physicians depending on their medical specialty. According to these researchers, patients' self-management behaviors can be influenced by physicians' beliefs and behaviors. De Berardis et al. [75] compared diabetes consultations in 125 diabetes outpatient clinics and 103 general practices for process and intermediate outcomes (frequency of examinations, $\mathrm{HbA1c}$, blood pressure, and cholesterol levels) over a period of 2 years. They found significant better results for the majority of the process measures, and for cholesterol levels, in the specialized diabetes outpatient clinics as compared to the general practices. In particular, care by the same specialist in a diabetes outpatient clinic ensured better quality of care in comparison with other care options. Yet, these studies did not relate to diabetes technology use. Thus, our results add preliminary evidence that differences do not just affect traditional but also technology-supported diabetes care (e.g., diabetes app use), with specialist care promoting technology-supported self-management to a greater extent than care by GPs. Reasons for this might be found in a connection between more extensive knowledge about diabetes and mHealth apps, and longer consultation duration afforded by specialists. It is also possible that government initiatives to promote mHealth have been promoted more extensively with specialists. However, given that we did not interview healthcare professionals, these are assumptions that need to be examined in further research.

Examining the use of technology in physician-patient relationships further, other studies generally discussed the usefulness of health apps for physician-patient interaction, for example, in shared decision-making [36]. Abbasgholizadeh et al. [36] reported mixed results for technology-supported physician-patient interactions; for example, better accessibility to data, improved efficiency for the physician, real-time connectivity, or remote decision-making on the one hand, but diminished quality of care through overuse of mHealth, increased health disparities due to lacking mHealth access, or lack of mHealth regulation, on the other hand. 
In terms of non-professional support, the patients' personal network was perceived as either facilitating or hindering the use of mobile technology for selfmanagement, depending respectively on the presence of supportive or unsupportive behaviors (Study 1). Moreover, support by this non-professional network significantly predicted patients' use of diabetes apps, with lower family and friend support increasing the likelihood of using diabetes apps (Study 2). Potential explanations for the negative relationship could be that certain patient groups are substituting technology to compensate for a lack of perceived or actual social support (e.g. [76]). There is an emergent research field examining loneliness and Internet use [77, 78], with studies suggesting that technology can offer a solution for chronically ill patients who feel isolated with their disease and who search for a (technological) solution to overcome their lack of social connection [79]. As mentioned earlier, support by relatives and friends is not necessarily always positive, for example, when unsupportive behaviors or miscarried helping occur $[16,22,26]$. Thus, support can be sought elsewhere, in this case, via technology substitution. Conversely, high social support by family and friends might nullify the need for additional technology to support self-care, which might explain why higher social support accompanies less technology use. In general, our results support the extant literature showing that the patients' social network influences attitudes towards innovation, which influence innovation adoption behaviors in return [80].

\section{Future research}

Future research needs to examine aspects of social support influencing mHealth use, also comparing the influence of professional versus non-professional support on mHealth use. Apart from the social influence of health professionals and of family and friends on mHealth use as studied here, previous studies show that "peer" patients also play an important role as sources of information and of empowerment for patients [38, 81]. Thus, firstly, follow-up research should include the role of patient peers. Secondly, the investigation can be extended from physicians to other healthcare professionals involved (e.g., nurse educators). Thirdly, mHealth studies should extend their theoretical foundations beyond technology adoption theories. There are few theories applied in mHealth research, which mainly relies on traditional behavior change theories $[82,83]$. To investigate factors influencing and predicting technology use for selfmanagement, a broader theoretical foundation needs to be available, overcoming the limitations of a very narrow range of theories. Fourthly, even though the socioeconomic and demographic factors included in the regression analysis (e.g., age, insurance coverage) did not predict the use of diabetes apps, it has to be further examined if these factors have an impact on the results, like the association between the specialty of the physician and the use of diabetes technology, or the negative association between non-professional support and technology use. Similarly, and fifth, an influence of app characteristics and app quality on diabetes app use is to be expected and follow-up research has to examine how these app characteristics interrelate with other factors influencing app use for diabetes self-management, including aspects of social support.

\section{Implications for research, policy and practice}

While our study focused on diabetes apps, these results can equally inform mHealth research in other health domains involving self-management, including various chronic conditions such as heart diseases, obesity, asthma, stroke, cancer, arthritis, hypertension, multiple sclerosis, etc. [84, 85]. Even though there are specific characteristics for each disease, general knowledge about technology use for self-management can be helpful across health conditions to design technology accordingly.

For diabetes policy and practice, the study results suggest that there are notable differences in patient groups regarding diabetes app use, with diabetes patients being a heterogeneous group with varying needs [86]. Segmentation theory needs to be used to tailor diabetes app characteristics specifically for subgroups with varying preferences and needs regarding technology (also considering socioeconomic, cultural, and demographic differences). Moreover, influencing factors need to be considered when designing technology for diabetes care, like the influence of aspects of social support and social influence [87]. Both healthcare professional supervision and family/friend support can influence technologysupported self-management. In particular, the care provided by GPs was perceived as unsatisfactory by most diabetes patients in the Study 1 sample. This resulted in less mobile technology use as compared to specialist supervision, which deficiency should be addressed to achieve equal care for all patients. The inclusion of relatives in (technology-supported) self-care should be further investigated depending on patient preferences and the usefulness of support provided (to avoid misguided support).

\section{Study limitations}

Study limitations included the small sample size of the online survey, which limited sophisticated multi-variate data analysis [4] and broad generalizability. Considerable effort was undertaken to achieve a larger sample size (extension of the field phase, seeking contact with official care organizations, seeking cooperation with healthcare professionals, repeated invitations for survey 
participation), yet without success. Singaporean citizens suffering from diabetes receive a large amount of invitations for study participation since the government declared "the war against diabetes" in 2016 [88], so these are a prized yet scarce resource for research. Due to the cross-sectional nature of the study design, final conclusions about causality could not be drawn. Additionally, due to the recruitment method a certain degree of selfselection was unavoidable (over-representation of support group members and educated participants). The sample was therefore not representative for all Singaporean individuals with diabetes; however, we managed to include participants of the main Singaporean cultural backgrounds in the sample (Chinese, Malay, Indian). These three groups comprise 97\% of Singaporeans [89]. Finally, triangulation of the study findings with results on diabetes app features and quality $[4,5]$ was not undertaken here due to length limitations.

\section{Conclusion}

Our study results indicated that aspects of both professional and non-professional support have an impact on the use of mobile self-management technology by diabetes patients. However, the results also showed that the effects of support are not always positive for technology use. This leads to the conclusion that social support in diabetes self-management needs to be considered and analyzed in a differentiated manner when looking into social support as a predictor of technology use.

\section{Abbreviations}

T1DM/T2DM: Type 1/Type 2 Diabetes Mellitus; GP: General practitioner; HCP: Healthcare professional; IP: Interview participant; UTAUT: Unified Theory of Acceptance and Use of Technology; DAFNE: Dose Adjustment for Normal Eating

\section{Acknowledgements}

Not applicable.

\section{Authors' contributions}

NBS collected, analyzed and interpreted the data, and drafted the manuscript. CR and AC supported data collection and data analysis, reviewed the manuscript, and provided detailed comments for improvement. The authors read and approved the final manuscript.

\section{Funding}

Study funding was provided by the Nanyang Technological University (research grant number M4081081).

\section{Availability of data and materials}

The (anonymized, non-identifiable) datasets used and/or analyzed during the current study are available from the corresponding author on reasonable request. Additional information on the methodology (questionnaires, survey) can be found online [63].

\section{Ethics approval and consent to participate}

Ethical review and approval was provided by the Nanyang Technological University Review Board (IRB-2016-01-012). Informed consent for participation was signed by all study participants.

Consent for publication

Not applicable.

\section{Competing interests}

Not applicable, none to be reported.

\section{Author details}

'Department of Health Services Research and Policy, Research School of Population Health, College of Health and Medicine, Australian National University, Mills Rd, Acton ACT 2601, Canberra, Australia. ${ }^{2}$ Wee Kim Wee School of Communication and Information, Nanyang Technological University, 31 Nanyang Link, Singapore 637718, Singapore. ${ }^{3}$ Department of Media and Communication Studies, University of Erfurt, Nordhaeuser Str. 63, 99089 Erfurt, Germany.

Received: 18 February 2020 Accepted: 29 June 2020

Published online: 07 July 2020

\section{References}

1. Rosland AM, Kieffer E, Israel B, Cofield M, Palmisano G, Sinco B, et al. When is social support important? The association of family support and professional support with specific diabetes self-management behaviors. J Gen Intern Med. 2008;23(12):1992-9 PubMed PMID: 18855075. Pubmed Central PMCID: 2596525.

2. Strom JL, Egede LE. The impact of social support on outcomes in adult patients with type 2 diabetes: a systematic review. Curr Diab Rep. 2012; 12(6):769-81 PubMed PMID: 22949135. Pubmed Central PMCID: 3490012.

3. Burner E, Lam CN, DeRoss R, Kagawa-Singer M, Menchine M, Arora S. Using mobile health to improve social support for low-income Latino patients with diabetes: a mixed-methods analysis of the feasibility trial of TExT-MED + FANS. Diabetes Technol Therapeutics. 2018;20(1):39-48 PubMed PMID: 29227155. Pubmed Central PMCID: 5770080.

4. Brew-Sam N. App use and patient empowerment in diabetes selfmanagement - advancing theory-guided mHealth research. Wiesbaden: Springer; 2020.

5. Brew-Sam N, Chib A. How do smart device apps for diabetes selfmanagement correspond with theoretical indicators of empowerment? An analysis of app features. Int J Technol Assess Health Care. 2019;35(2):150-9.

6. Funnell MM, Anderson RM. Empowerment and self-management of diabetes. Clinical Diabetes. 2004;22(3):123-7.

7. Wilkinson A, Whitehead L, Ritchie L. Factors influencing the ability to selfmanage diabetes for adults living with type 1 or 2 diabetes. Int J Nurs Stud. 2014:51(1):111-22

8. Peyrot M, Rubin RR, Lauritzen T, Snoek FJ, Matthews DR, Skovlund SE. Psychosocial problems and barriers to improved diabetes management: results of the cross-National Diabetes Attitudes, wishes and needs (DAWN) study. Diabet Med. 2005;22(10):1379-85 PubMed PMID: 16176200.

9. Hunter $\mathrm{CM}$. Understanding diabetes and the role of psychology in its prevention and treatment. Am Psychol. 2016;71(7):515-25 PubMed PMID: 27690481.

10. Ahola AJ, Groop PH. Barriers to self-management of diabetes. Diabet Med. 2013;30(4):413-20 PubMed PMID: 23278342.

11. Rodriguez KM. Intrinsic and extrinsic factors affecting patient engagement in diabetes self-management: perspectives of a certified diabetes educator. Clin Ther. 2013;35(2):170-8 PubMed PMID: 23411000.

12. van Dam HA, van der Horst F, van den Borne B, Ryckman R, Crebolder $H$. Provider-patient interaction in diabetes care: effects on patient selfcare and outcomes: a systematic review. Patient Educ Couns. 2003;51(1): $17-28$.

13. Heisler M, Bouknight RR, Hayward RA, Smith DM, Kerr EA. The relative importance of physician communication, participatory decision making, and patient understanding in diabetes self-management. J Gen Intern Med. 2002;17(4):243-52

14. Patel NJ, Datye KA, Jaser SS. Importance of patient-provider communication to adherence in adolescents with type 1 diabetes. Healthcare (Basel). 2018; 6(2):30. PubMed PMID: 29597246. Pubmed Central PMCID: 6023481.

15. Kaselitz E, Shah M, Choi H, Heisler M. Peer characteristics associated with improved glycemic control in a randomized controlled trial of a reciprocal peer support program for diabetes. Chronic IIIn. 2019;15(2):149-156 PubMed PMID: 29343089.

16. Grant RW, Schmittdiel JA. Adults with diabetes who perceive family members' behaviour as unsupportive are less adherent to their medication regimen. Evid Based Nurs. 2013;16(1):15-6 PubMed PMID: 22952019. 
17. Armour $T A$, Norris $S L$, Jack $L J$, Zhang $X$, Fisher $L$. The effectiveness of family interventions in people with diabetes mellitus: a systematic review. Diabet Med. 2005;22(10):1295-305 PubMed PMID: 16176186.

18. Heisler M, Vijan S, Makki F, Piette JD. Diabetes control with reciprocal peer support versus nurse care management: a randomized trial. Ann Intern Med. 2010;153(8):507-15 PubMed PMID: 20956707. Pubmed Central PMCID: 4117390.

19. Gensichen J, Von Korff M, Rutter CM, Seelig MD, Ludman EJ, Lin EH, et al. Physician support for diabetes patients and clinical outcomes. BMC Public Health. 2009;9:367 PubMed PMID: 19788726. Pubmed Central PMCID: 2762989.

20. Kaplan SH, Greenfield S, Ware JE Jr. Assessing the effects of physicianpatient interactions on the outcomes of chronic disease. Med Care. 1989; 27(3 Suppl):S110-27 PubMed PMID: 2646486.

21. Emanuel EJ, Emanuel LL. Four models of the physician-patient relationship. J Am Med Assoc JAMA. 1992;267(16):2221-26.

22. Helgeson VS, Mascatelli K, Seltman H, Korytkowski M, Hausmann LR. Implications of supportive and unsupportive behavior for couples with newly diagnosed diabetes. Health Psychol. 2016;35(10):1047-58 PubMed PMID: 27280364. Pubmed Central PMCID: 5033701.

23. The Lancet. Family matters in diabetes care. Lancet Diabetes Endocrinol. 2018;6(12):911.

24. Whitehead L, Jacob E, Towell A, Abu-Qamar M, Cole-Heath A. The role of the family in supporting the self-management of chronic conditions: a qualitative systematic review. J Clin Nurs. 2018;27(1-2):22-30 PubMed PMID: 28231630.

25. Kowitt SD, Ayala GX, Cherrington AL, Horton LA, Safford MM, Soto S, et al. Examining the support peer supporters provide using structural equation modeling: nondirective and directive support in diabetes management. Ann Behav Med. 2017;51(6):810-21 PubMed PMID: 28417438.

26. Bennich BB, Roder ME, Overgaard D, Egerod I, Munch L, Knop FK, et al. Supportive and non-supportive interactions in families with a type 2 diabetes patient: an integrative review. Diabetol Metab Syndr. 2017;9:57 PubMed PMID: 28736580. Pubmed Central PMCID: 5521150

27. Carter-Edwards L, Skelly AH, Cagle CS, Appel SJ. "They care but don't understand": family support of African American women with type 2 diabetes. Diabetes Educ. 2004;30(3):493-501.

28. Sanjari M, Peyrovi $\mathrm{H}$, Mehrdad N. Managing children with diabetes within the family: entering into the diabetes orbit. J Diabetes Metab Disord. 2016; $15: 7$.

29. Mayberry LS, Osborn CY. Family support, medication adherence, and glycemic control among adults with type 2 diabetes. Diabetes Care. 2012;35(6):1239-45 PubMed PMID: 22538012. Pubmed Central PMCID: 3357235.

30. Harris MA. The Family's involvement in diabetes care and the problem of "miscarried helping". European Endocrinol. 2006;2:20.

31. Schiel R, Bambauer R, Steveling A. Technology in Diabetes Treatment: update and future. Artif Organs. 2018;42(11):1017-27 PubMed PMID: 30334582.

32. Hsu WC, Lau KH, Huang R, Ghiloni S, Le H, Gilroy S, et al. Utilization of a cloud-based diabetes management program for insulin initiation and titration enables collaborative decision making between healthcare providers and patients. Diabetes Technol Therapeutics. 2016;18(2):59-67 PubMed PMID: 26645932. Pubmed Central PMCID: 4753582.

33. Srivastava P, Verma A, Geronimo C, Button TM. Behavior stages of a physician- and coach-supported cloud-based diabetes prevention program for people with prediabetes. SAGE Open Med. 2019;7:2050312119841986 PubMed PMID: 31105938. Pubmed Central PMCID: 6509979

34. Cheng C, Xin G, Xiaoli W, Chuanwei C, Xiaoming S, Yimin Z, et al. Evaluation of the implementation and effect of the healthcare cloud information platform for diabetes self-management: a case study in Shanghai. Int $J$ Health Plann Manage. 2019;34(3):986-97 PubMed PMID: 31368129.

35. Wehbe R, Curcio E, Gajjar M, Yadlapati A. Technology and its influence on the doctor-patient relationship. Int Cardiovasc Forum J. 2015;3:38-9.

36. Abbasgholizadeh Rahimi S, Menear M, Robitaille H, Légaré F. Are mobile health applications useful for supporting shared decision making in diagnostic and treatment decisions? Glob Health Action. 2017;10(sup3):1332259.

37. Gabarron E, Arsand E, Wynn R. Social media use in interventions for diabetes: rapid evidence-based review. J Med Internet Res. 2018;20(8): e10303 PubMed PMID: 30097421. Pubmed Central PMCID: 6109225.
38. Litchman ML, Edelman LS, Donaldson GW. Effect of diabetes online community engagement on health indicators: cross-sectional study. JMIR Diabetes. 2018;3(2):e8 PubMed PMID: 30291079. Pubmed Central PMCID: 6238850.

39. Oh HJ, Lee B. The effect of computer-mediated social support in online communities on patient empowerment and doctor-patient communication Health Commun. 2012;27(1):30-41 PubMed PMID: 21797714.

40. Gomez-Galvez P, Suarez Mejias C, Fernandez-Luque L. Social media for empowering people with diabetes: current status and future trends. In: Conference proceedings, 37th annual international conference of the IEEE, engineering in medicine and biology society (EMBC); 2015. p. 2135-8. PubMed PMID: 26736711.

41. Maki KG, O'Mally AK. Analyzing online social support within the type 1 diabetes community. In: Sekalala S, Niezgoda BC, editors. Global perspectives on health communication in the age of social media. Hershey: IGI Global; 2018. p. 59-84.

42. Burner E, Mercado J, Hernandez-Saenz A, Peters A, Mack W, BaezcondeGarbanati $L$, et al. Design and patient characteristics of the randomized controlled trial TEXT-MED+FANS a test of mHealth augmented social support added to a patient-focused text-messaging intervention for emergency department patients with poorly controlled diabetes. Contemp Clin Trials. 2019;80:1-8.

43. Omboni S, Caserini M, Coronetti C. Telemedicine and M-health in hypertension management: technologies, applications and clinical evidence. High Blood Pressure Cardiovasc Prev. 2016;23(3):187-96 PubMed PMID: 27072129.

44. Fortuna KL, DiMilia PR, Lohman MC, Bruce ML, Zubritsky CD, Halaby $M R$, et al. Feasibility, acceptability, and preliminary effectiveness of a peer-delivered and technology supported self-management intervention for older adults with serious mental illness. Psychiatry Q. 2018;89(2): 293-305.

45. Wang W, Su Y, Gao G. Determinants of mHealth effectiveness: evidence from a large-scale experiment. SSRN [04/23/2018]. Available from: https:// ssrn.com/abstract=3167637.

46. Mayberry LS, Berg CA, Harper KJ, Osborn CY. The design, usability, and feasibility of a family-focused diabetes self-care support mHealth intervention for diverse, low-income adults with type 2 diabetes. J Diabetes Res. 2016;2016:7586385.

47. Yan L. Good intentions, bad outcomes: the effects of mismatches between social support and health outcomes in an online weight loss community. Prod Oper Manag. 2018;27(1):9-27.

48. Danaher BG, Brendryen H, Seeley JR, Tyler MS, Woolley T. From black box to toolbox: outlining device functionality, engagement activities, and the pervasive information architecture of mHealth interventions. Internet Interv. 2015;2(1):91-101.

49. Zhu Z, Liu Y, Che X, Chen X. Moderating factors influencing adoption of a mobile chronic disease management system in China. Inform Health Soc Care. 2018;43(1):22-41.

50. Bin Azhar FA, Dhillon JS. A systematic review of factors influencing the effective use of mHealth apps for self-care. In: 3rd International Conference on Computer and Information Sciences (ICCOINS). Kuala Lumpur: IEEE; 2016. p. 191-6.

51. Venkatesh V, Morris MG, Davis GB, Davis FD. User acceptance of information technology: toward a unified view. MIS Q. 2003;27(3):425-78.

52. Free C, Phillips G, Galli L, Watson L, Felix L, Edwards P, et al. The effectiveness of mobile-health technology-based health behaviour change or disease management interventions for health care consumers: a systematic review. PLoS Med. 2013;10(1):e1001362.

53. Chib A, van Velthoven MH, Car J. mHealth adoption in low-resource environments: a review of the use of mobile healthcare in developing countries. J Health Commun. 2015;20(1):4-34 PubMed PMID: 24673171.

54. Hoque R, Sorwar G. Understanding factors influencing the adoption of mHealth by the elderly: an extension of the UTAUT model. Int J Med Inform. 2017;101:75-84.

55. Quaosar G, Hoque MR, Bao Y. Investigating factors affecting elderly's intention to use m-health services: an empirical study. Telemed and eHealth. 2018;24(4):309-14.

56. Apolinário-Hagen J, Menzel M, Hennemann S, Salewski C. Acceptance of mobile health apps for disease management among people with multiple sclerosis: web-based survey study. JMIR Formative Res. 2018; 2(2):e11977. 
57. Breil B, Kremer L, Hennemann S, Apolinário-Hagen J. Acceptance of mHealth apps for self-management among people with hypertension. Stud Health Technol Inform. 2019;267:282-8.

58. Apolinário-Hagen J, Hennemann S, Fritsche L, Drüge M, Breil B. Determinant factors of public acceptance of stress management apps: survey study. JMIR Mental Health. 2019;6(11):e15373.

59. Zhang Y, Liu C, Luo S, Xie Y, Liu F, Li X, et al. Factors influencing patients' intentions to use diabetes management apps based on an extended unified theory of acceptance and use of technology model: web-based survey. J Med Internet Res. 2019;21(8):e15023.

60. Liu D, Maimaitijiang R, Gu J, Zhong S, Zhou M, Wu Z, et al. Using the unified theory of acceptance and use of technology (UTAUT) to investigate the intention to use physical activity apps: cross-sectional survey. JMIR Mhealth Uhealth. 2019;7(9):e13127 PubMed PMID: 31507269.

61. Reading M, Baik D, Beauchemin M, Hickey KT, Merrill JA. Factors influencing sustained engagement with ECG self-monitoring: perspectives from patients and health care providers. Appl Clinical Informatics. 2018;9(4):772-81 PubMed PMID: 30304745 . Pubmed Central PMCID: 6179719.

62. Wisdom J, Creswell JW. Mixed methods: integrating quantitative and qualitative data collection and analysis while studying patient-centered medical home models. Rockville: Agency for Healthcare Research and Quality, U.S. Department of Health and Human Services; 2013.

63. Brew-Sam N. Appendix. 2020. In: App use and patient empowerment in diabetes self-management - advancing theory-guided mHealth research. Wiesbaden: Springer. Available from: https://link.springer.com/chapter/10.1 007/978-3-658-29357-4_4

64. Parks MR. Weak and strong tie relationships. In: Berger $C$, Roloff M, editors. The international encyclopedia of interpersonal communication. New Jersey: Wiley; 2015. p. 1-5.

65. Braun V, Clarke V. Using thematic analysis in psychology. Qual Res Psychol. 2006;3(2):77-101.

66. Mays N, Pope C. Assessing quality in qualitative research. BMJ. 2000;320:502.

67. Krebs P, Duncan DT. Health app use among US mobile phone owners: a national survey. JMIR Mhealth Uhealth. 2015;3(4):e101 PubMed PMID: 26537656. Pubmed Central PMCID: 4704953.

68. Fitzgerald JT, Davis WK, Connell CM, Hess GE, Funnell MM, Hiss RG. Development and validation of the diabetes care profile. Eval Health Prof. 1996;19(2):208-30.

69. Fitzgerald JT, Davis WK, Connell CM, Hess GE, Funnell MM, Hiss RG. Diabetes care profile: Medical University of South Carolina; 1996. [04/13/2018]. Available from: http://academicdepartments.musc.edu/family_medicine/ remar/dcp.htm.

70. Anderson RM, Fitzgerald JT, Gruppen LD, Funnell MM, Oh MS. The diabetes empowerment scale-short form (DES-SF). Diabetes Care. 2003;26(5):1641-2.

71. Mantwill S, Fiordelli M, Ludolph R, Schulz PJ. EMPOWER - support of patient empowerment by an intelligent self-management pathway for patients: study protocol. BMC Med Inform Decis Mak. 2015;15:18 PubMed PMID: 25890197. Pubmed Central PMCID: 4372173

72. Toobert DJ, Hampson SE, Glasgow RE. The summary of diabetes self-care activities measure. Diabetes Care. 2000;23(7):943-50.

73. International Diabetes Federation IDF. Type 2 diabetes 2019 [09/18/2019]. Available from: https://idf.org/52-about-diabetes.html

74. Koizumi J, Matsukura T, Oyama O, Maeda T, Nomura H, Asano A, et al. Influence of physician specialty on treatment goals for diabetic patients: results of a survey given to the members of the Ishikawa medical association. General Med. 2008;9(2):71-9.

75. De Berardis G, Pellegrini F, Franciosi M, Belfiglio M, Di Nardo B, Greenfield S, et al. Quality of care and outcomes in type 2 diabetic patients: a comparison between general practice and diabetes clinics. Diabetes Care. 2004;27(2):398-406 PubMed PMID: 14747220.

76. Swickert RJ, Hittner JB, Harris JL, Herring JA. Relationships among internet use, personality, and social support. Comput Hum Behav. 2002;18(4):437-51.

77. Cacioppo JT, Cacioppo S. Social relationships and health: the toxic effects of perceived social isolation. Soc Personal Psychol Compass. 2014;8(2):58-72 PubMed PMID: 24839458. Pubmed Central PMCID: 4021390

78. Nowland R, Necka EA, Cacioppo JT. Loneliness and social internet use: pathways to reconnection in a digital world? Perspect Psychol Sci. 2018; 13(1):70-87 PubMed PMID: 28937910.
79. Rasmussen B, Dunning P, O'Connell B. Young women with diabetes: using internet communication to create stability during life transitions. J Clin Nurs. 2007;16(3A):17-24 PubMed PMID: 17518865

80. Talukder M, Quazi A. The impact of social influence on individuals' adoption of innovation. J Organ Comput Electron Commer. 2011;21(2):111-35.

81. Ramirez AG, Turner BJ. The role of peer patients in chronic disease management. Ann Intern Med. 2010;153(8):544-5 PubMed PMID: 20956712.

82. Jones KR, Lekhak N, Kaewluang N. Using mobile phones and short message service to deliver self-management interventions for chronic conditions: a meta-review. Worldviews Evidence-based Nurs. 2014;11(2):81-8.

83. Riley WT, Rivera DE, Atienza AA, Nilsen W, Allison SM, Mermelstein R. Health behavior models in the age of mobile interventions: are our theories up to the task? Transl Behav Med. 2011;1(1):53-71.

84. Centers for Disease Control and Prevention. Chronic Disease Overview 2017 [09/06/2018]. Available from: www.cdc.gov/chronicdisease/overview/index. htm.

85. Council for Medical Schemes. Chronic Diseases List 2018 [09/06/2018]. Available from: www.medicalschemes.com/medical_schemes_pmb/ chronic_disease_list.htm.

86. Scheibe M, Reichelt J, Bellmann M, Kirch W. Acceptance factors of mobile apps for diabetes by patients aged 50 or older: a qualitative study. Medicine2.0. 2015;4(1):e1.

87. Chib A, Lin S. Theoretical advancements in mHealth: a systematic review of mobile apps. J Health Commun. 2018;23(10-11):909-55.

88. $\mathrm{MOH}$ Ministry of Health, Singapore. War on Diabetes 2019 [10/24/2019]. Available from: https://www.moh.gov.sg/wodcj.

89. SingStat. Population Trends 2019 [2019]. Available from: https://www. singstat.gov.sg/-/media/files/publications/population/population2019.pdf.

\section{Publisher's Note}

Springer Nature remains neutral with regard to jurisdictional claims in published maps and institutional affiliations.

Ready to submit your research? Choose BMC and benefit from:

- fast, convenient online submission

- thorough peer review by experienced researchers in your field

- rapid publication on acceptance

- support for research data, including large and complex data types

- gold Open Access which fosters wider collaboration and increased citations

- maximum visibility for your research: over $100 \mathrm{M}$ website views per year

At BMC, research is always in progress.

Learn more biomedcentral.com/submissions 